\title{
Mangiferin inhibition of proliferation and induction of apoptosis in human prostate cancer cells is correlated with downregulation of B-cell lymphoma-2 and upregulation of microRNA-182
}

\author{
MINGLIN LI, HUILI MA, LIXIN YANG and PENG LI \\ Department of Urology, Nanyang City Center Hospital, Nanyang, Henan 473009, P.R. China
}

Received October 9, 2014; Accepted August 17, 2015

DOI: $10.3892 / \mathrm{ol} .2015 .3924$

\begin{abstract}
Mangiferin, a flavonoid extracted from the mango tree, possesses anti-inflammatory, antibacterial, anti-herpes simplex and antitumor activity, and is able to affect immune function. The present study investigated the anticancer effects of mangiferin treatment on PC3 human prostate cancer cells, and the potential underlying mechanisms. In the present study, an MTT assay was used to analyze the proliferation of PC3 cells. Subsequently, flow cytometry and colorimetric assay kits were utilized to measure the PC3 cell apoptotic rate. The expression levels of B-cell lymphoma-2 (Bcl-2) and microRNA-182 (miR-182) were detected using western blot analysis and quantitative reverse transcription-polymerase chain reaction, respectively. Finally, miR-182 and anti-miR-182 were transfected into PC3 cells, which were used to investigate the effects of mangiferin. Mangiferin treatment reduced the proliferation of PC3 human prostate cancer cells in a concentration- and time-dependent manner. In addition, mangiferin was able to promote apoptosis and induce the caspase-3 activity of PC3 human prostate cancer cells. Mangiferin treatment was also able to significantly reduce Bcl-2 expression levels and enhance miR-182 expression in PC3 cells. Finally, it was observed that mangiferin inhibited proliferation and induced apoptosis in PC3 human prostate cancer cells, and this effect was correlated with downregulation of Bcl-2 and upregulation of miR-182.
\end{abstract}

\section{Introduction}

Prostate cancer is a disease that affects older males, and is one of the most common malignant tumors amongst males in Europe (1). Previously, prostate cancer was observed relatively rarely in China; however, in recent years the incidence of prostate cancer and associated mortality rates have been increasing (1).

Correspondence to: Miss. Huili Ma, Department of Urology, Nanyang City Center Hospital, 312 Gongnong Road, Nanyang, Henan 473009, P.R. China

E-mail: huilimamr@163.com

Key words: mangiferin, B-cell lymphoma-2, microRNA-182, prostate cancer
In 2008, the worldwide standardized incidence rate of prostate cancer was 28.5/100,000 and the standardized mortality rate was 7.5/100,000 (2-4). Therefore, prostate cancer has become a significant area of research.

Cell apoptosis may be inseparable from the development of prostate cancer. Apoptosis, or programmed cell death, differs from necrosis, the natural cell death process (5). Reduced apoptosis and increased proliferation are thought to be the primary mechanisms underlying the formation of the majority of tumors. Inhibition of apoptosis may also possess a significant role in the progression of prostate cancer, and B-cell lymphoma-2 (Bcl-2) is thought to be one of the most significant genes required for apoptosis (6).

MicroRNAs (miRs) are a class of endogenously expressed non-protein encoding RNAs (2). Mature miRs are single-stranded and consist of 22 nucleotides (7). Previous studies have indicated that miRs may be involved in human tumorigenesis and development. Numerous tumors exhibit alterations in miR expression levels, and these miRs may have a role in tumorigenesis, functioning as cancer genes or tumor suppressor genes (8). Casanova-Salas et al (9) demonstrated that miR-182 was a potential biomarker for prostate cancer diagnosis, prognosis predictions and for improvement of the predictive capability of existing biomarkers. Siva et al (10) reported that molecular assays may be used to detect miR-182 expression in prostate cancer.

Mangiferin is a flavonoid, extracted from the mango tree; and studies have revealed that it is capable of inhibiting the growth of liver and colon cancer cells, K562 leukemia cells and other tumor cells (11-14). Pharmacological experiments indicate that mangiferin is capable of effectively treating chronic bronchitis (3). Mangiferin is the primary active ingredient in the Tibetan capillary treatment of hepatitis and is the antiviral active ingredient of rhizoma anemarrhenae, a Traditional Chinese Medicine (4). In the present study, the anticancer effects of mangiferin on prostate cancer cells were investigated and its apoptosis-inducing effects were studied at the cellular level, with the aim of identifying the underlying mechanisms.

\section{Materials and methods}

Experimental materials. Mangiferin (purity, >98\%) was obtained from Sigma-Aldrich (St. Louis, MO, USA). The chemical structure of mangiferin is illustrated in Fig. 1. 
RPMI-1640, fetal bovine serum (FBS) and penicillin/streptomycin were obtained from Gibco Life Technologies (Carlsbad, CA, USA). MTT and chemiluminescence reagent kits were purchased from Tiangen Biotech Co., Ltd. (Beijing, China). Cleaved caspase- 3 and caspase- 9 colorimetric assay, bicinchoninic acid (BCA) Protein assay and UN1Q-10 Column Trizol Total RNA Isolation kit were purchased from Sangon Biotech Co., Ltd. (Shanghai, China). TRIzol reagent and oligo (dT) primers were purchased from Invitrogen Life Technologies (Carlsbad, CA, USA). SYBR chemistry and Annexin V-fluorescein isothiocyanate (FITC)/propidium iodide (PI) Apoptosis Detection kits were obtained from Shanghai BestBio Co. (Shanghai, China).

Cell culture. PC3 human prostate cancer cells were purchased from Shanghai Cell Bank of the Chinese Academy of Sciences (Shanghai, China) and cultured in RPMI-1640 medium containing $10 \%(\mathrm{v} / \mathrm{v})$ FBS with penicillin $(100 \mathrm{U} / \mathrm{ml}) /$ streptomycin $(100 \mathrm{U} / \mathrm{ml})$ in $5 \% \mathrm{CO}_{2}$ at $37^{\circ} \mathrm{C}$. Approximately every 2-3 days, the culture medium was removed and replaced. PC3 cells were treated with mangiferin in complete RPMI-1640 medium.

Cell proliferation assay. PC3 cells were cultured with mangiferin (10, 20 and $40 \mu \mathrm{M})$ for $0,24,48$ and $72 \mathrm{~h}$. Proliferation of PC3 cells was quantified using an MTT assay. PC3 cells $\left(5 \times 10^{4} / \mathrm{ml}\right)$ were seeded into flat-bottomed 96 -well culture plates and $\sim 10 \mu 1$ MTT $(5 \mathrm{mg} / \mathrm{ml})$ was added to each well. Cells were incubated for $4 \mathrm{~h}$ in $5 \% \mathrm{CO}_{2}$ at $37^{\circ} \mathrm{C}$. Following this, the culture medium was removed, and $200 \mu$ ldimethyl sulfoxide (Invitrogen; Thermo Fisher Scientific, Inc., Waltham, MA, USA) was added to each well and incubated for 10-20 min. The absorbance was measured at $540 \mathrm{~nm}$ using a Labsystems Multiskan MS Plate Reader (Thermo Fisher Scientific, Inc.).

Flow cytometry. PC3 cells were cultured with mangiferin (10, 20 and $40 \mu \mathrm{M}$ ) for $72 \mathrm{~h}$. Cells were collected by centrifugation at $3,000 \mathrm{x} \mathrm{g}$ for $10 \mathrm{~min}$ at $4^{\circ} \mathrm{C}$ and washed twice with ice-cold phosphate buffered saline (PBS). In accordance with the manufacturer's protocol, cells were incubated with $5 \mu \mathrm{l}$ Annexin V-FITC on ice for $30 \mathrm{~min}$ in the dark. PI $(10 \mu \mathrm{l})$ was then added to the cells and they were subsequently observed using flow cytometry, using a LSRII (BD Biosciences, San Jose, CA, USA).

Caspase-3 activity assays. PC3 cells were cultured with mangiferin (10, 20 and $40 \mu \mathrm{M})$ for $72 \mathrm{~h}$. Caspase-3 activity was detected using the cleaved caspase- 3 colorimetric assay kit (Sangon Biotech Co., Ltd.) according to the manufacturer's instructions. The fluorescence of caspase- 3 activity was detected at a wavelength of $405 \mathrm{~nm}$, using a Labsystems Multiskan MS Plate Reader.

Western blot analysis of Bcl-2 expression. PC3 cells were treated with various concentrations of mangiferin $(10,20$ and $40 \mu \mathrm{M}$ ) for $72 \mathrm{~h}$. Cells were collected using centrifugation at 3,000 $\mathrm{x}$ g for $10 \mathrm{~min}$ and washed twice with ice-cold PBS. Cells were resuspended with $200 \mu \mathrm{l}$ protein lysate and centrifuged at $12,300 \mathrm{x} \mathrm{g}$ for $15 \mathrm{~min}$ at $4^{\circ} \mathrm{C}$ for $15 \mathrm{~min}$ at $4^{\circ} \mathrm{C}$. Protein concentration was determined using the BCA Protein

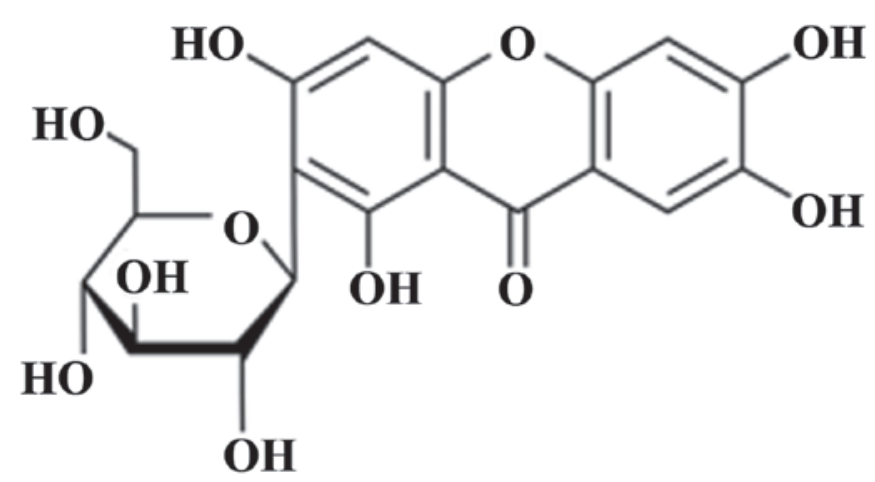

Figure 1. Chemical structure of mangiferin.

Assay kit (Sangon Biotech Co., Ltd.). Approximately $50 \mu \mathrm{g}$ protein was electrophoresed using a $10 \%$ polyacrylamide gel (Beyotime Institute of Biotechnology, Nanjing, China) containing SDS. Proteins were transferred onto nitrocellulose membranes (Millipore Corporation, Bedford, MA, USA) at $4^{\circ} \mathrm{C}$ for 2-4 h. The membranes were blocked in 5\% non-fat milk for 1-2 $\mathrm{h}$ and subsequently incubated with rabbit antiBcl-2 (15071S; 1:1,000; Cell Signaling Technology, Boston, MA, USA) and rabbit anti-human $\beta$-actin (D110001-0025; 1:500; Sangon Biotech Co., Ltd.) antibodies overnight at $4^{\circ} \mathrm{C}$ with agitation. Following washing with Tris-buffered saline and Tween-20 PBST (with 0.1\% Tween 20; Beyotime Institute of Biotechnology) monoclonal anti-rabbit immunoglobulin IgG conjugates (C2162; 1:1,000, Beijing Applygen Technologies, Inc., Beijing, China) for $2 \mathrm{~h}$. Subsequently, membranes were washed with TBST and bands were observed using an enhanced chemiluminescence kit Stripping Buffer for Western Blot (PA114, Tiangen Biotech Co., Ltd.).

Reverse transcription-quantitative polymerase chain reaction $(R T-q P C R)$. PC3 cells were cultured with mangiferin $(10,20$ and $40 \mu \mathrm{M})$ for $72 \mathrm{~h}$. TRIzol reagent (Invitrogen Life Technologies) was used to extract total RNA, and total RNA was purified using an RNA kit (Sangon Biotech Co., Ltd.). Complementary DNA was reverse transcribed using oligo (dT) primers (Invitrogen Life Technologies). SYBR chemistry (BestBio, Co.) was used for PCR. All primers were purchased from Sangon Biotech Co., Ltd. The following primer sequences were used: miR-182 forward, 5'-GGGGTACCCTTC AGGAAGCTGGTTTC-3' and miR-182 reverse, 5'-GGGATA TCTACATGTGAGGCAGGTTCTCAC-3'; U6 forward, 5'-CGCTTCGGCAGCACATATACTA-3' and U6 reverse, 5'-CGCTTCACGAATTTGCGTGTCA-3'.

miRNA transfection. miR-182 mimic and miR-182 inhibitor were purchased from Sangon Biotech Co., Ltd. miR-182 mimic $(100 \mathrm{nmol} / \mathrm{l})$ and miR-182 inhibitor (100 nmol/l) transfections were conducted in PC3 cells using Lipofectomine ${ }^{\circledR}$ 2000 (Invitrogen Life Technologies) according to the manufacturer's instructions. Following transfection for 6 h, culture medium was removed and replaced with complete medium. Subsequently, PC3 cells were incubated for $18 \mathrm{~h}$ in $5 \% \mathrm{CO}_{2}$ at $37^{\circ} \mathrm{C}$, prior to treatment with various concentrations of mangiferin $(50 \mu \mathrm{M})$ for $72 \mathrm{~h}$. 


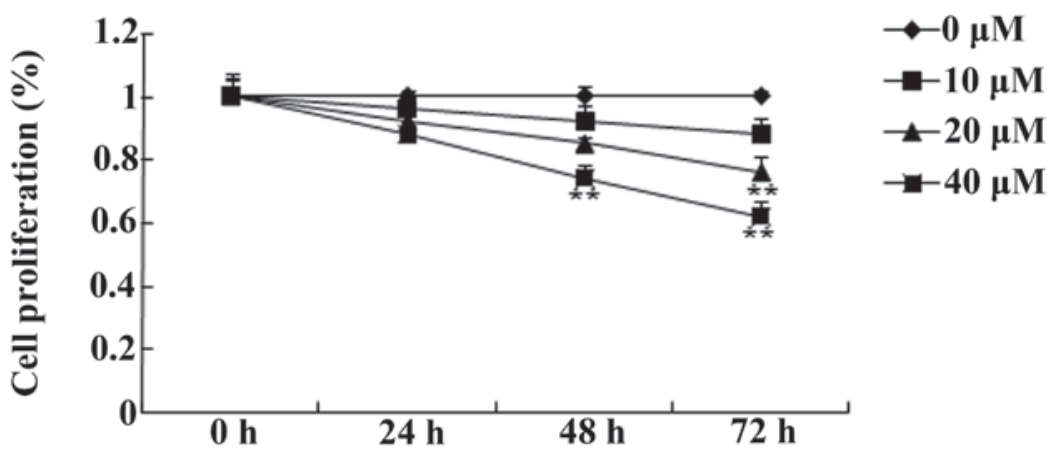

Figure 2. Treatment with mangiferin has an antiproliferative effect on PC 3 cells. Values are expressed as the mean \pm standard deviation. ${ }^{* *} \mathrm{P}<0.01$ compared with $0 \mu \mathrm{M}$ mangiferin treatment control group.
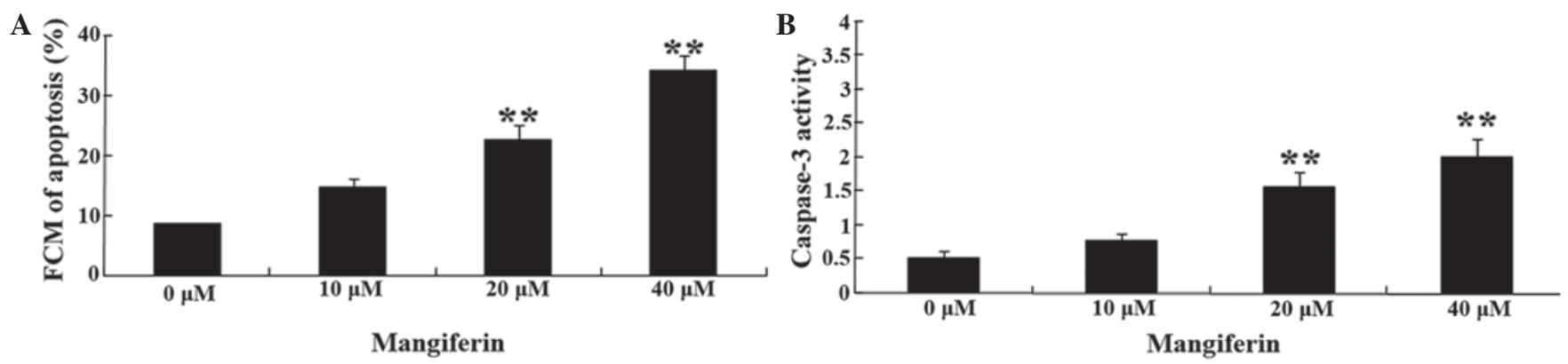

Figure 3. Treatment with mangiferin enhances the apoptosis of PC3 cells. (A) Statistical analysis of cellular apoptosis levels and (B) caspase-3 activity. Values are expressed as the mean \pm standard deviation. ${ }^{* *} \mathrm{P}<0.01$ compared with $0 \mu \mathrm{M}$ mangiferin treatment control group. FCM, flow cytometry.
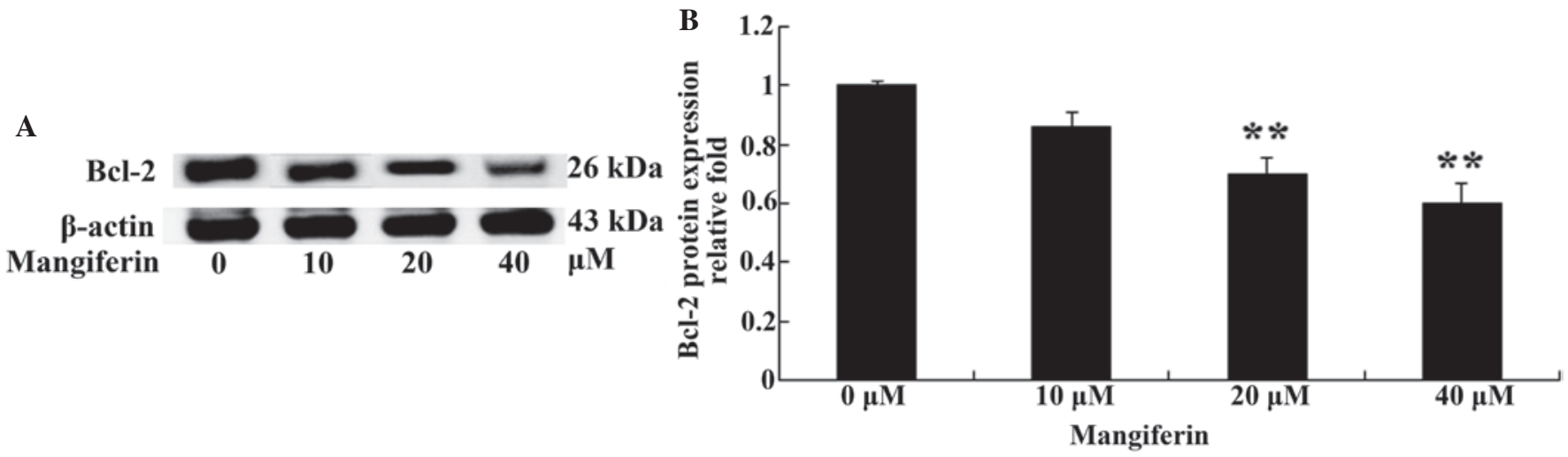

Figure 4. Bcl-2 expression is downregulated following treatment with mangiferin. (A) Effects of mangiferin on Bcl-2 and (B) statistical analysis of Bcl-2 protein expression levels. Values are expressed as the mean \pm standard deviation. ${ }^{* * *} \mathrm{P}<0.01$ compared with $0 \mu \mathrm{M}$ mangiferin treatment control group. $\mathrm{Bcl}-2$, B-cell lymphoma-2.

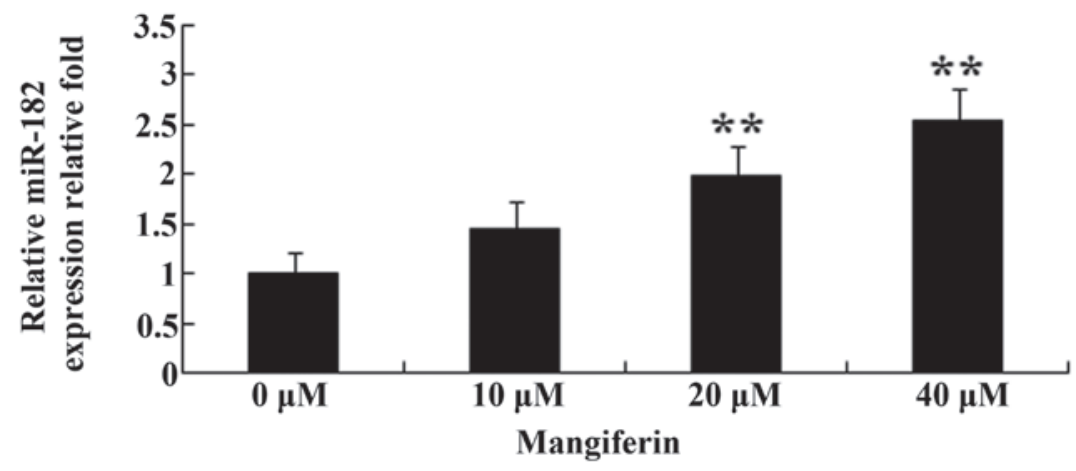

Figure 5. miR-182 expression is increased following treatment with mangiferin. Values are expressed as the mean \pm standard deviation. ${ }^{* *} \mathrm{P}<0.01$ compared with $0 \mu \mathrm{M}$ mangiferin treatment control group. miR-182, microRNA-182. 


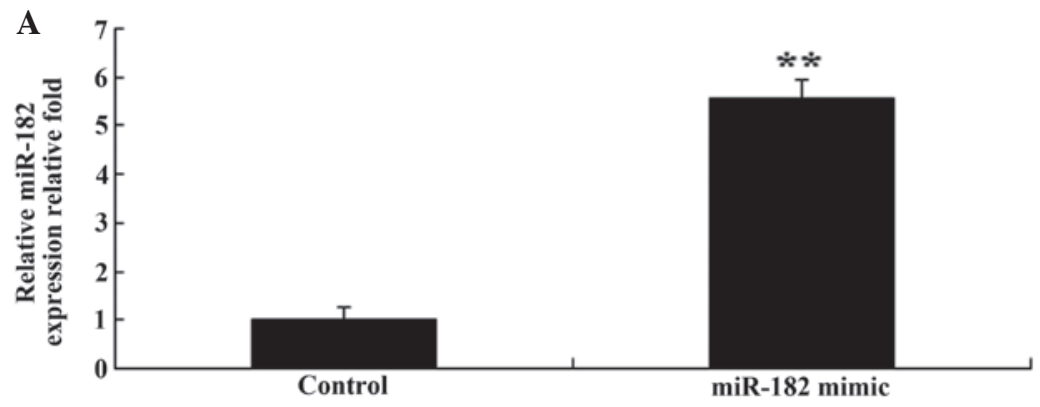

$26 \mathrm{kDa}$

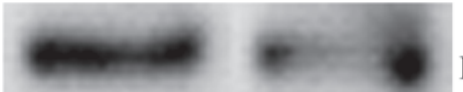

Bcl-2

$43 \mathrm{kDa}$

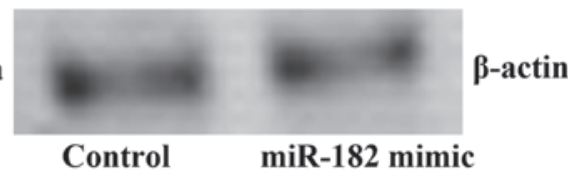

Control

Figure 6. Overexpression of miR-182 and Bcl-2 expression following transfection with an miR-182 mimic. (A) miR-182 expression of PC3 cells and (B) Bcl-2 protein expression was inhibited in PC3 cells following miR-182 mimic transfection. ${ }^{* *} \mathrm{P}<0.01$ compared with control group. miR, microRNA; Bcl-2, B-cell lymphoma-2.

A

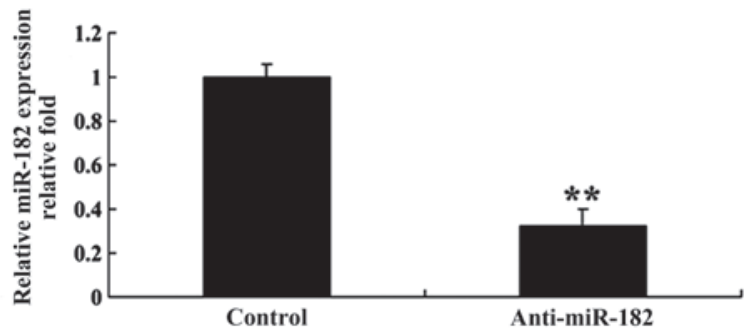

C

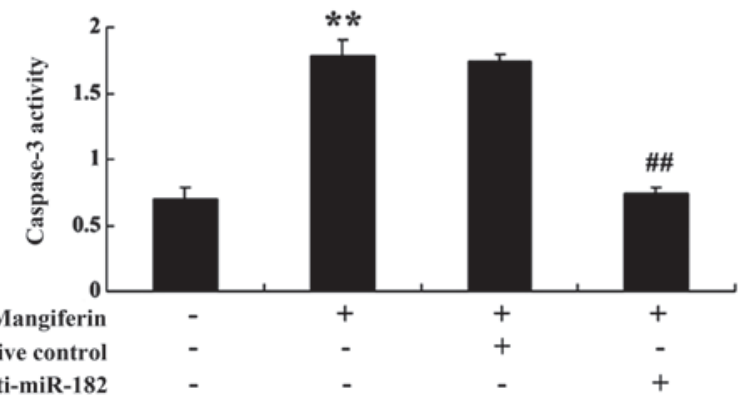

B

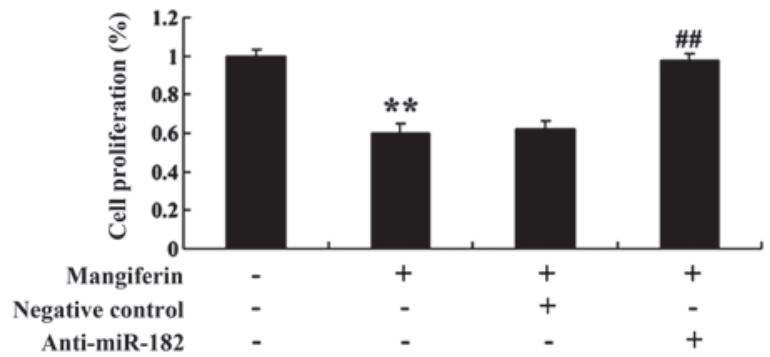

D

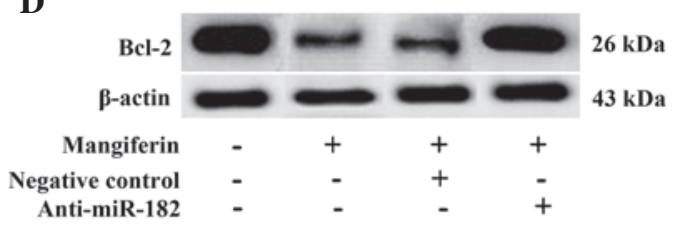

Figure 7. miR-182 inhibitor is able to reduce the effect of mangiferin treatment. (A) Anti-miR-182 reduced the effect of mangiferin treatment on the expression of miR-182 in PC3 cells. (B) Following treatment with mangiferin $(50 \mu \mathrm{M})$ for $72 \mathrm{~h}$, anti-miR-182 significantly promoted the proliferation of PC3 cells. (C) Following treatment with mangiferin $(50 \mu \mathrm{M})$ for $72 \mathrm{~h}$, anti-miR-182 inhibited apoptosis of PC3 cells. (D) Anti-miR-182 significantly enhanced Bcl-2 activity in PC3 cells following mangiferin $(50 \mu \mathrm{M})$ treatment at $72 \mathrm{~h}$. ${ }^{* *} \mathrm{P}<0.01$ compared with $0 \mu \mathrm{M}$ mangiferin treatment control group, and ${ }^{\# \#} \mathrm{P}<0.01$ compared with mangiferin-treated group transfected with negative control. miR, microRNA; Bcl-2, B-cell lymphoma-2.

Statistical analysis. Data analysis was performed using SPSS version 17.0 (SPSS Inc., Chicago, IL, USA). Data were expressed as the mean \pm standard deviation. Differences were assessed using the two-tailed Student's t-test. $\mathrm{P}<0.05$ was considered to indicate a statistically significant difference.

\section{Results}

Mangiferin exerts an antiproliferative effect on PC3 cells. To investigate the potential effects of mangiferin $(0,10,20$ and $40 \mu \mathrm{M})$ on the proliferation of PC3 cells, the present study used an MTT assay to examine antiproliferative activity. Mangiferin inhibited the proliferation of PC3 cells in a concentration-dependent manner. When PC3 cells were treated with mangiferin at a concentration of $20 \mu \mathrm{M}$ for $72 \mathrm{~h}$, or with mangiferin at a concentration of $40 \mu \mathrm{m}$ for 48 or $72 \mathrm{~h}$, the proliferation of PC3 cells was significantly reduced compared with that of the control group treated with $0 \mu \mathrm{M}$ mangiferin (Fig. 2).
Mangiferin enhances apoptosis of PC3 cells. To assess the effect of mangiferin $(0,10,20$ and $40 \mu \mathrm{M})$ on the apoptosis of PC3 cells, apoptosis and caspase-3 activity were analyzed. Mangiferin accelerated apoptosis and enhanced the caspase-3 activity of PC3 cells in a concentration-dependent manner. In addition, when treated with mangiferin $(20$ and $40 \mu \mathrm{M})$ for $72 \mathrm{~h}$, the apoptosis of PC3 cells was significantly increased compared with that of the control group treated with $0 \mu \mathrm{M}$ mangiferin (Fig. 3A). Furthermore, the caspase-3 activity of PC3 cells treated with 20 and $40 \mu \mathrm{M}$ mangiferin was significantly enhanced compared with that of the control group treated with $0 \mu \mathrm{M}$ mangiferin (Fig. 3B).

Bcl-2 expression is downregulated following mangiferin treatment. In order to elucidate the effect of mangiferin on the expression of $\mathrm{Bcl}-2, \mathrm{PC} 3$ cells were exposed to $0,10,20$ and $40 \mu \mathrm{M}$ mangiferin for $72 \mathrm{~h}$, and the expression of $\mathrm{Bcl}-2$ was analyzed. $\mathrm{Bcl}-2$ protein expression was downregulated 
following exposure to mangiferin at all concentrations. Furthermore, mangiferin (20 and $40 \mu \mathrm{M})$ was able to significantly reduce Bcl-2 expression levels in PC3 cells compared with those of the control group treated with $0 \mu \mathrm{M}$ mangiferin (Fig. 4A and B).

miR-182 expression is increased following mangiferin treatment. To examine the effect of mangiferin treatment on the expression of miR-182, PC3 cells were exposed to $0,10,20$ and $40 \mu \mathrm{M}$ mangiferin for $72 \mathrm{~h}$, and the expression of miR-182 was detected. Following treatment with mangiferin (20 and $40 \mu \mathrm{M}$ ) for $72 \mathrm{~h}$, miR-182 expression was significantly increased in PC3 cells (Fig. 5).

Overexpression of miR-182 inhibits Bcl-2 expression in PC3 cells. In order to further understand miR-182 expression in PC 3 cells, an miR-182 mimic was transfected into PC 3 cells. It was observed that miR-182 overexpression significantly inhibited Bcl-2 expression in PC3 cells (Fig. 6A and B).

miR-182 inhibitor abrogates the effect of mangiferin. To further evaluate the correlation between miR-182 expression levels and the mechanism of antiproliferative activity of mangiferin, miR-182 inhibitor was transfected into PC 3 cells. The results of the present study demonstrated that transfection with miR-182 inhibitor significantly reduced miR-182 expression levels in PC3 cells (Fig. 7A). However, miR-182 inhibitor was also able to significantly reduce the antiproliferative and apoptotic effects of mangiferin $(50 \mu \mathrm{M})$ on PC3 cells (Fig. 7B and C). Therefore, miR-182 inhibitor may be capable of rescuing Bcl-2 expression in PC3 cells (Fig. 7D).

\section{Discussion}

Prostate cancer is one of the most common types of cancer in the male reproductive system (5). Due to socioeconomic development, as well as changes in lifestyle and environment, the incidence and mortality rates of male primary prostate cancer tumors are changing (15). A recent study revealed that the incidence and development of prostate cancer may be associated with the dysregulation of apoptosis regulatory genes (16). Proliferation of the cells that lose their response to apoptosis, may contribute to the invasion and metastasis of prostate tumors. In the present study, it was revealed that mangiferin was capable of inhibiting the proliferation of PC 3 cells in a concentrationand time-dependent manner. Pan et al (11) demonstrated that mangiferin was able to inhibit the proliferation of human nasopharyngeal carcinoma cells through G2/M arrest and induction of early apoptosis. In the present study, mangiferin accelerated the apoptotic rate and enhanced the caspase- 3 activity of PC3 human prostate cancer cells in a concentration-dependent manner. Taken together, these results indicate that mangiferin may promote apoptosis and increase caspase- 3 activity in cancer cell lines (17).

The Bcl-2 protein family contains significant genes involved in the regulation of apoptosis (18). The primary anti-apoptotic and pro-apoptotic members of the Bcl-2 family regulate apoptosis by controlling mitochondrial function (19). $\mathrm{Bcl}-2$ inhibits apoptosis by preventing an increase in cytoplasmic calcium concentration (6). In previous studies, Bcl-2 expression has been observed to be a notable feature in certain human malignant tumors; and Bcl-2 is now believed to be an anti-apoptotic gene that promotes tumor occurrence through inhibiting apoptosis and prolonging the survival of cells (20). In the present study, mangiferin was able to significantly reduce the Bcl-2 expression levels in PC3 cells. Pan et al (11) reported that mangiferin induced cell apoptosis through $\mathrm{Bcl}-2$ and $\mathrm{Bcl}-2$ associated X protein (Bax) expression. Pal et al (21) hypothesized that mangiferin attenuates diabetic nephropathy by inhibiting Bcl-2 and Bax expression.

miRs are a class of small molecule RNA, involved in the regulation of gene expression, which have a significant role in cell growth, differentiation, apoptosis and tumorigenesis (7). Greater than half of human miR genes are located in a genomic region of a tumor-associated or fragile site. Expression profiling has been utilized to reveal that the expression of specific miRs may be indicative of the tumor stage and differentiation state (22). In the present study, treatment with mangiferin significantly increased miR-182 expression levels in PC 3 cells. Notably, upregulation of miR-182 suppressed Bcl-2 expression in PC3 cells. In addition, suppression of miR-182 expression reduced the effect of mangiferin on PC3 cells and increased the expression levels of Bcl-2 in PC3 cells. Peng et al (8) reported inhibition of proliferation in PC3 human prostate cancer cells following atorvastatin treatment, due to downregulation of $\mathrm{Bcl}-2$ and upregulation of miR-182. Overexpression of miR-182 has been observed to suppress the growth of uveal melanoma cells via a reduction in Bcl-2 expression levels (23).

Mangiferin is double-benzene pyrone flavonoid that exhibits antioxidant, hypoglycemic and renal protective effects. Mangiferin possesses anti-inflammatory, antibacterial and anti-herpes simplex virus effects; it affects gallbladder and immune function, as well as a protective effect on the simulated high altitude hypoxia liver injury (24-26). In conclusion, the results of the present study indicated that mangiferin is capable of exerting an antitumor effect on PC3 human prostate cancer cells, potentially via downregulation of Bcl-2 and upregulation of miR-182. In addition, the effects of mangiferin may be able to contribute to the characterization of prostate cancer and the development of novel therapies.

\section{References}

1. Zhai X, Han Q, Shan Z, Qu X, Guo L and Zhou Y: Dual specificity phosphatase 6 suppresses the growth and metastasis of prostate cancer cells. Mol Med Rep 10: 3052-3058, 2014.

2. Ferlay J, Shin HR, Bray F, Forman D, Mathers C and Parkin DM: Estimates of worldwide burden of cancer in 2008: GLOBOCAN 2008. Int J Cancer 127: 2893-2917, 2010.

3. Znaor A, Lortet-Tieulent J, Jemal A and Bray F: International variations and trends in testicular cancer incidence and mortality. Eur Urol 65: 1095-1106, 2014.

4. Askari F, Parizi MK, Jessri M and Rashidkhani B: Fruit and vegetable intake in relation to prostate cancer in Iranian men: A case-control study. Asian Pac J Cancer Prev 15: 5223-5227, 2014.

5. Ummanni R, Lehnigk U, Zimmermann U, Woenckhaus C, Walther R and Giebel J: Immunohistochemical expression of caspase-1 and -9 , uncleaved caspase- 3 and -6 , cleaved caspase-3 and -6 as well as Bcl-2 in benign epithelium and cancer of the prostate. Exp Ther Med 1: 47-52, 2010.

6. Sambantham S, Radha M, Paramasivam A, Anandan B, Malathi R, Chandra SR and Jayaraman G: Molecular mechanism underlying hesperetin-induced apoptosis by in silico analysis and in prostate cancer PC-3 cells. Asian Pac J Cancer Prev 14: 4347-4352, 2013. 
7. Liu DF, Wu JT, Wang JM, Liu QZ, Gao ZL and Liu YX: MicroRNA expression profile analysis reveals diagnostic biomarker for human prostate cancer. Asian Pac J Cancer Prev 13: 3313-3317, 2012

8. Peng X, Li W, Yuan L, et al: Inhibition of proliferation and induction of autophagy by atorvastatin in PC3 prostate cancer cells correlate with downregulation of $\mathrm{Bcl} 2$ and upregulation of miR-182 and p21. PLoS One 8: e70442, 2013.

9. Casanova-Salas I, Rubio-Briones J, Calatrava A, Mancarella C, Masiá E, Casanova J, Fernández-Serra A, Rubio L, Ramírez-Backhaus M, Armiñán A, et al: Identification of miR-187 and miR-182 as biomarkers of early diagnosis and prognosis in patients with prostate cancer treated with radical prostatectomy. J Urol 192: 252-259, 2014

10. Siva AC, Nelson LJ, Fleischer CL, Majlessi M, Becker MM, Vessella RL and Reynolds MA: Molecular assays for the detection of microRNAs in prostate cancer. Mol Cancer 8: 17, 2009.

11. Pan LL, Wang AY, Huang YQ, Luo Y and Ling M: Mangiferin induces apoptosis by regulating $\mathrm{Bcl}-2$ and $\mathrm{Bax}$ expression in the CNE2 nasopharyngeal carcinoma cell line. Asian Pac J Cancer Prev 15: 7065-7068, 2014.

12. Rajendran P,Ekambaram G and Sakthisekaran D: Cytoprotective effect of mangiferin on benzo(a)pyrene-induced lung carcinogenesis in swiss albino mice. Basic Clin Pharmacol Toxicol 103: 137-142, 2008

13. Yoshimi N, Matsunaga K, Katayama M, Yamada Y, Kuno T, Qiao Z, Hara A, Yamahara J and Mori H: The inhibitory effects of mangiferin, a naturally occurring glucosylxanthone, in bowel carcinogenesis of male F344 rats. Cancer Lett 163: 163-170, 2001

14. Peng ZG, Luo J, Xia LH, Chen Y and Song SJ: CML cell line K562 cell apoptosis induced by mangiferin. Zhongguo Shi Yan Xue Ye Xue Za Zhi 12: 590-594, 2004 (In Chinese).

15. Choi ES, Han G, Park SK, Lee K, Kim HJ, Cho SD and Kim HM: A248, a novel synthetic HDAC inhibitor, induces apoptosis through the inhibition of specificity protein 1 and its downstream proteins in human prostate cancer cells. Mol Med Rep 8: 195-200, 2013.

16. Cheng J, Li L, Liu Y, Wang Z, Zhu X and Bai X: Interleukin-1 $\alpha$ induces immunosuppression by mesenchymal stem cells promoting the growth of prostate cancer cells. Mol Med Rep 6: 955-960, 2012
17. du Plessis-Stoman D, du Preez J and van de Venter M: Combination treatment with oxaliplatin and mangiferin causes increased apoptosis and downregulation of $\mathrm{NF \kappa B}$ in cancer cell lines. Afr J Tradit Complement Altern Med 8: 177-184, 2011.

18. Ye QF, Zhang YC, Peng XQ, Long Z, Ming YZ and He LY: Silencing Notch-1 induces apoptosis and increases the chemosensitivity of prostate cancer cells to docetaxel through Bcl-2 and Bax. Oncol Lett 3: 879-884, 2012.

19. Meng FM, Yang JB, Yang CH, Jiang Y, Zhou YF, Yu B and Yang $\mathrm{H}$ : Vitexicarpin induces apoptosis in human prostate carcinoma PC-3 cells through G2/M phase arrest. Asian Pac J Cancer Prev 13: 6369-6374, 2012.

20. Ahn YT, Shin IJ, Kim JM, Kim YS, Lee C, Ju SA and An WG: Counteracting the activation of pAkt by inhibition of MEK/Erk inhibition reduces actin disruption-mediated apoptosis in PTEN-null PC3M prostate cancer cell lines. Oncol Lett 6: 1383-1389, 2013

21. Pal PB, Sinha K and Sil PC: Mangiferin attenuates diabetic nephropathy by inhibiting oxidative stress mediated signaling cascade, TNF $\alpha$ related and mitochondrial dependent apoptotic pathways in streptozotocin-induced diabetic rats. PLoS One 9: e107220, 2014.

22. Tong SJ, Liu J, Wang X and Qu LX: microRNA-181 promotes prostate cancer cell proliferation by regulating DAX-1 expression. Exp Ther Med 8: 1296-1300, 2014.23.

23. Yan D, Dong XD, Chen X, Yao S, Wang L, Wang J, Wang C, Hu DN, Qu J and Tu L: Role of microRNA-182 in posterior uveal melanoma: Regulation of tumor development through MITF, BCL2 and cyclin D2. PLoS One 7: e40967, 2012.

24. Sánchez GM, Re L, Giuliani A, Núñez-Sellés AJ, Davison GP and León-Fernández OS: Protective effects of Mangifera indica L. extract, mangiferin and selected antioxidants against TPA-induced biomolecules oxidation and peritoneal macrophage activation in mice. Pharmacol Res 42: 565-573, 2000.

25. García D, Delgado R, Ubeira FM and Leiro J: Modulation of rat macrophage function by the Mangifera indica $\mathrm{L}$. extracts Vimang and mangiferin. Int Immunopharmacol 2: 797-806, 2002.

26. Muruganandan S, Gupta S, Kataria M, Lal J and Gupta PK: Mangiferin protects the streptozotocin-induced oxidative damage to cardiac and renal tissues in rats. Toxicology 176: $165-173,2002$. 